\title{
МЕТОД МНОГОЦЕЛЕВОГО РАСПРЕДЕЛЕНИЯ ОГРАНИЧЕНИИ ЭЛЕКТРИЧЕСКОЙ НАГРУЗКИ
}

M. MOTUS, H. NURSTE, S. SOOSAAR. ELEKTRILISE KOORMUSE PIIRAMISTE JAOTAMISE MITMEKRITERIAALNE MEETOD

M. MOTUS, H. NURSTE, S. SOOSAAR. A MULTICRITERIAL METHOD FOR DISPATCHING ELECTRIC LOAD LIMITATIONS

(Представил И. Эпик)

Целью данной работы является разработка метода оптимизации распределения ограничений на электрическую нагрузку между предприятиями с минимальными для народного хозяйства суммарными потерями. Исходная задача сводится к оцениванию последствий на предприятиях, вызванных введением ограничений, сравнению этих последствий между собой, ранжированию предприятий и, на основе полученных данных, распределению ограничений между ними.

Анализ исходной информации на уровне предприятий позволяет определить показатели, которые используются для оценки достижения поставленных целей. Нами выдвигаются шесть целей:

1. Достижение минимального снижения суммарной валовой продукции по всем предприятиям (ограничению подлежат в первую очередь предприятия, производящие относительно энергоемкую валовую продукцию, рубб $/ \kappa B T \cdot u)$.

II. Уменьшение суммарной величины ущерба, наносимого предприятию введением ограничений (ограничению подлежат прежде всего предприятия, испытывающие при этом наименьший удельный ущерб, $p y б(\kappa B T \cdot ч)$.

III. Наложение ограничений прежде всего на предприятия с бо́льшими возможностями форсирования производства во внепиковое время (т. е. имеющих наименьшее отношение максимально потребляемой мощности к установленной).

IV. Наложение ограничений прежде всего на предприятия с бо́льшими возможностями перемещения максимума нагрузки в течение суток (т. е. допускающих временные ограничения в использовании максимальной мощности в сутки).

V. Наложение ограничений прежде всего на предприятия с бо́льшими возможностями регулирования производства в течение года (т. е. допускающих временные ограничения в использовании максимальной мощности за год). 
VI. Сведение до минимума числа рабочих, производительность которых страдает в связи с введением ограничений на потребляемую мощность (т. е. ограничению подлежат прежде всего предприятия с бо́льшими значениями максимальной мощности на производственный персонал, кВт/чел).

Ранжирование предприятий производится по критерию многоцелевой эффективности с использованием экспертных оценок важности целей $\left[{ }^{1}\right]$ :

$$
E=\sum_{i=1}^{k} e_{i} v_{i}
$$

где $v_{i}$ - весовой коэффициент относительной важности $i$-й цели; $e_{i}$ - степень достижения цели; $k$ - тисло целей. Весовые коэффициенты $v_{i}$ определяются путем опроса экспертов. В итоге каждое предприятие получает значение $E$. Чем меньше значение $E$, тем больше оснований ограничить это предприятие.

Описанная методика применялась для составления графиков ограничения нагрузки промышленных потребителей в конкретной энергосистеме. Ранжирование предприятий производилось по отраслям, поскольку часть показателей можно было оценить только в среднем. Для определения весовых коэффициентов $v_{i}$ были опрошены эксперты из Госплана, энергосистемы и научно-исследовательских организаций. В результате получены следующие значения $v_{i}$ : I $-0,223$; II $-0,185$; III - 0,170; IV - 0,168; V - 0,135; VI - 0,119.

Расчеты по формуле (1) дали следующие значения критерия многоцелевой эффективности по отраслям:

Отрасль

1. Пищевая

0,183

2. Легкая

0,173

3. Приборостроение

0,124

4. Электротехническая

0,113

5. Химическая

0,102

6. Лесная и деревообрабатывающая

0,090

7. Строительные материалы

0,076

8. Машиностроение и металлообработка

0,074

9. Топливная (добыча)

0,065

При введении ограничений энергосистеме может потребоваться коррекция рангов отраслей. Для учета межотраслевых технологических связей и социальных аспектов были опрошены те же эксперты и проранжированы отрасли. В результате опроса очередность отраслей получилась следующей (в скобках - значения нормированных оценок): топливная $(0,282)$, пищевая $(0,194)$, химическая $(0,085)$, строительные материалы $(0,071)$, машиностроение и металлообработка $(0,069)$, легкая $(0,067)$, электротехническая $(0,061)$, приборостроение $(0,057)$, лесная и деревообрабатывающая $(0,052)$. Топливная и пищевая отрасли получили наивысшие нормированные оценки по сравнению с другими. Остальные отрасли могут рассматриваться как равные, поскольку их оценки отличаются друг от друга сравнительно мало.

Итак, как оценки относительной важности цели, так и ранжирование отраслей по связям говорят о том, что в пищевой промышленности допустимы лишь относительно слабые ограничения. Топливная промышленность по оценкам относительной важности цели допускает наи- 
большие ограничения, а по ранжированию отраслей' по связям - наименьшие. Такое противоречие объясняется тем, что в случае дефицича топлива для производства элекгроэнергии ограничение электрической мощности при добыче может привести к более острому дефициту.

При распределении ограничений на электрическую нагрузку между отраслями по критерию многоцелевой эффективности использовался принцип: каждый киловатт договорной нагрузки отрасли ограничивается обратно пропорционально значению $E$ отрасли, т. е.

$$
\underset{i}{N o r p}=N_{i} N \text { orp } / E_{i} \sum_{i=1}^{q}\left(N_{i} / E_{i}\right),
$$

где $i$ - индекс отрасли; $N^{\text {огр }}$ - общая величина ограничения; $N_{i}$ - договорная нагрузка отрасли; $q$ - число отраслей.

Остальные ограничивающие факторы учитываются энергосистемой в рабочем порядке в виде поправок к основной схеме.

Целесообразность применения изложенной методики подтверждена получением существенного экономического эффекта в конкретной энергосистеме.

\section{ЛИТ Е РАТ У РА}

1. Окороков В. Р., Управление электроэнергетическими системами. (Технико-экономические принципы и методы), Л., Изд-во ЛГУ, 1976.

Ннститут термофизики и электрофизики Академии наук Эстонской ССР

Поступила в редакцию 1/XII 1980 